\title{
Pharmacological versus microvascular decompression approaches for the treatment of trigeminal neuralgia: clinical outcomes and direct costs
}

\author{
This article was published in the following Dove Press journal: \\ Journal of Pain Research \\ 23 August 2011 \\ Number of times this article has been viewed
}

\section{Laurinda Lemos ${ }^{1,2}$ \\ Carlos Alegria ${ }^{3}$ \\ Joana Oliveira ${ }^{3}$ \\ Ana Machado 2 \\ Pedro Oliveira ${ }^{4}$ \\ Armando Almeida'}

'Life and Health Sciences Research Institute (ICVS), School of Health Sciences, Campus de Gualtar, University of Minho, Braga, Portugal; ${ }^{2}$ Hospital Center of Alto Ave, Unit of Fafe, Fafe, Portugal; ${ }^{3}$ Department of Neurosurgery, Hospital São Marcos; ${ }^{4}$ Products and Systems Engineering, Campus de Azurém, University of Minho, Guimarães, Portugal
Correspondence: Armando Almeida Life and Health Sciences Research Institute (ICVS), School of Health Sciences, Campus de Gualtar, University of Minho, 47 I 0-057 Braga - Portugal

Tel +35I-253-604808

Fax +35I-253-604809

Email aalmeida@ecsaude.uminho.pt

\begin{abstract}
In idiopathic trigeminal neuralgia (TN) the neuroimaging evaluation is usually normal, but in some cases a vascular compression of trigeminal nerve root is present. Although the latter condition may be referred to surgery, drug therapy is usually the first approach to control pain. This study compared the clinical outcome and direct costs of (1) a traditional treatment (carbamazepine [CBZ] in monotherapy [CBZ protocol]), (2) the association of gabapentin (GBP) and analgesic block of trigger-points with ropivacaine (ROP) (GBP+ROP protocol), and (3) a common TN surgery, microvascular decompression of the trigeminal nerve (MVD protocol). Sixty-two TN patients were randomly treated during 4 weeks (CBZ $[n=23]$ and GBP+ROP $[n=17]$ protocols) from cases of idiopathic TN, or selected for MVD surgery $(n=22)$ due to intractable pain. Direct medical cost estimates were determined by the price of drugs in 2008 and the hospital costs. Pain was evaluated using the Numerical Rating Scale (NRS) and number of pain crises; the Hospital Anxiety and Depression Scale, Sickness Impact Profile, and satisfaction with treatment and hospital team were evaluated. Assessments were performed at day 0 and 6 months after the beginning of treatment. All protocols showed a clinical improvement of pain control at month 6 . The GBP+ROP protocol was the least expensive treatment, whereas surgery was the most expensive. With time, however, GBP+ROP tended to be the most and MVD the least expensive. No sequelae resulted in any patient after drug therapies, while after MDV surgery several patients showed important side effects. Data reinforce that, (1) TN patients should be carefully evaluated before choosing therapy for pain control, (2) different pharmacological approaches are available to initiate pain control at low costs, and (3) criteria for surgical interventions should be clearly defined due to important side effects, with the initial higher costs being strongly reduced with time.
\end{abstract}

Keywords: trigeminal neuralgia, carbamazepine, gabapentin associated with ropivacaine, microvascular decompression, clinical outcomes, direct costs

\section{Introduction}

Trigeminal neuralgia (TN) is a neuropathic pathology considered one of the most painful experiences patients can report, and no universal treatment is capable of reverting completely and definitely its intermittent paroxysmal excruciating pain crises. ${ }^{1} \mathrm{TN}$ is associated with impairment of daily functionality, reduced quality of life, ${ }^{2,3}$ and depression, ${ }^{4}$ to which contributes the overwhelming fear that pain can suddenly return again. Although the huge impact of pain in TN, which has an incidence of $4-5$ per $100,000^{5}$ or even higher, ${ }^{6}$ and a high prevalence in older patients should have been capable of resulting in clinical standards for TN treatment, this 
pathology is far from being well known and treated. In most cases the pathophysiology underlying TN is unknown or incompletely understood. Classical or idiopathic TN includes all cases without an established etiology (most of them) as well as those with potential vascular compression of the trigeminal nerve, whereas symptomatic TN results secondarily to cases such as tumors or multiple sclerosis. $^{7}$

$\mathrm{TN}$ is not controlled by classical analgesics, but the first-line therapy is pharmacological, being based on anticonvulsants (ACs), usually considered adjuvant analgesics in other pathologies but essential for neuropathic pain. Phenytoin in the past ${ }^{8,9}$ and now carbamazepine (CBZ) $)^{1,10-12}$ are first-line drugs in TN, followed by several second-line ACs such as lamotrigine, ${ }^{11,13}$ oxcarbazepine, ${ }^{14}$ gabapentin (GBP), ${ }^{1}$ and $\mathrm{CBZ}$ or GBP associated with peripheral block of triggerpoints with the local anesthetic ropivacaine (ROP); ; 15 these treatments changed the management of $\mathrm{TN}$, as previously it was almost exclusively surgical. Surprisingly, combination therapies, although common in epilepsy, have not been explored for TN management. ${ }^{3,15,16}$

Surgical intervention for $\mathrm{TN}$ is usually reserved for patients with intractable pain refractory to an adequate trial of at least 3 drugs including CBZ. ${ }^{1}$ The decision to perform a surgical approach should be based on the clinical presentation (including co-morbilities) of the patient and not primarily or exclusively on neuroimaging, ${ }^{1}$ as craniotomy is not without risks and fine detail alone at actual MRI spatial resolution cannot distinguish the pathological from the incidental when a vessel course is along the trigeminal nerve root. ${ }^{17,18}$ However, some patients may request surgical treatment due to intractable pain or strong adverse side effects. ${ }^{1}$ Microvascular decompression (MVD) of the trigeminal nerve root is a well established and superior method of choice among neurosurgical procedures ${ }^{19}$ in immediate (91\%-97\%) and long-term (53\%-70\%) relief of $\mathrm{TN},{ }^{12,20-22}$ but is associated with several risks, including different degrees of facial sensory loss as well as a small risk of mortality. ${ }^{1}$ Other surgical options include Gasser ganglion compression, glycerol gangliolysis, and radiofrequency thermocoagulation of the nerve, with the last producing initial pain relief in more than $90 \%$ and a complete pain relief after 5 years reaching $57 \%$ of patients, ${ }^{23}$ however, these cases are associated with a risk of anesthesia dolorosa $(0.6 \%-6 \%)$ and cases of transient or permanent cranial nerve palsies. ${ }^{1,23}$ Gamma knife radiosurgery is less invasive, the onset of pain relief following procedure possibly requiring $1-2$ months to occur, but then $30 \%-80 \%$ of cases report complete absence of pain; ${ }^{24-27}$ however, again, frequency of paresthesia and dysesthesia ranges from $3 \%-54 \%,{ }^{28,29}$ there is a steady rate of late failure, ${ }^{25}$ and the details of operative technique have a major influence on the clinical results. ${ }^{30,31}$ Nevertheless, in radiosurgical centers, this is a major surgery treatment for TN. ${ }^{27}$

From the above data, we should consider that the choice of drug and whether or not to operate and which procedure to choose should be individualized to the particular needs and conditions of each patient. ${ }^{1}$ The role of surgery versus pharmacotherapy in TN management remains uncertain as there are no studies dealing specifically with issues like "when should surgery be offered?". ${ }^{12}$ Additionally, only a few studies have evaluated the impact of TN costs to the patients, and compared only the cost-effectiveness of different surgical procedures. At longer follow-up intervals, MVD is predicted to be the most cost-effective surgery and should be considered the preferred operation for patients, compared with glycerol rhizotomy and stereotactic radiosurgery, ${ }^{32}$ whereas cyberknife radiosurgery is a cost-saving alternative compared with MVD. ${ }^{33}$ On the other hand, to the best of our knowledge, the costs associated with TN drug treatments have been analyzed only for pregabalin. ${ }^{34,35}$ However, no studies have evaluated the costs associated with different drug treatments compared with surgery. The objective of the present study was to compare the clinical outcome and direct costs of (1) a first-line pharmacological treatment (CBZ), (2) the therapeutical association of GBP and the peripheral analgesic block of TN trigger-points with ROP (GBP+ROP) and (3) a common TN surgery (MDV) in patients recruited from the same country region.

\section{Methods}

\section{Patients - inclusion and exclusion criteria}

This retrospective study includes a total of $62 \mathrm{TN}$ patients from the Hospital Center of Alto Ave - Fafe Pain Unit and the Hospital São Marcos in Braga, who were selected by different clinical teams as follows: patients under the traditional approach to $\mathrm{TN}$ were given $\mathrm{CBZ}$ in monotherapy (CBZ protocol; $n=23$ ) and were randomly selected in the continuation of a previous study of our group; ${ }^{15}$ patients submitted to an alternative TN approach were given GBP associated with the peripheral analgesic block of trigger-points with ROP $(\mathrm{GBP}+\mathrm{ROP}$ protocol; $\mathrm{n}=17)$ and were randomly selected in the continuation of another previous study of our group ${ }^{3}$ patients submitted to microvascular decompression of the trigeminal nerve (MVD protocol; $n=22$ ) were all those arriving at the Neurosurgery Department of Hospital São Marcos 
between 2005 and 2008 and indicated for surgery by this Hospital team (Table 1).

Patients from CBZ and GBP+ROP protocols were eligible for the study if they presented a pain intensity with a score $\geq 6$ measured by the Numerical Rating Scale (NRS), and met the consensus criteria for the diagnosis of primary (idiopathic) TN. ${ }^{36}$ The inclusion criteria were (1) the occurrence of episodes of facial paroxysmal pain in territory innervated by a branch of the trigeminal nerve (NRS score $\geq 6$ ), (2) presence of a normal neurological profile, and (3) presence of normal neuroimaging analysis. On the other hand, several exclusion criteria were also considered, ${ }^{3,15}$ including patient refusal to participate, clinical depressive condition, anticlotting therapy, secondary (symptomatic) $\mathrm{TN}$, altered neurological profile, neuroimaging alterations, association with other cranial nerve neuralgias, and proposed surgical intervention.

Patients following the surgical protocol (MVD) were selected by their intense intractable pain refractory to pharmacological therapy, or intolerable side effects of drugs. ${ }^{37}$ Thus, when arriving at the Neurosurgery Department of Hospital São Marcos (day 0), 21 of 22 patients showed NRS = 10 and all were being medicated (12 patients were taking $600 \mathrm{mg}$ /day of CBZ and 10 were taking $600 \mathrm{mg} /$ day of CBZ plus $600 \mathrm{mg} /$ day of GBP). This Neurosurgery Department does not have equipment for radiosurgery, thus MVD constitutes the major surgical approach for TN patients with intractable pain.

The therapeutical protocols used were accepted by the Hospital Ethical Committees (all three are actual therapies for TN pain control) and the patients were informed by the different clinical teams that: (1) they were going to be submitted to one of three (GBP+ROP protocol; see reference 3) or one of two (CBZ protocol $\left.{ }^{15}\right)$ pharmacological therapies, or to surgery (MVD protocol); (2) they could drop or change treatment if no pain control was achieved (CBZ and GBP+ROP protocols) or they would be continuing to take pharmacological agents if needed (MDV protocol). Patients signed an informed consent.

\section{Treatment protocols}

Patients were submitted to one of the following treatment protocols:

CBZ protocol - Treatment using only oral CBZ in monotherapy; patients entering this protocol received additionally a control injection of saline (the vehicle of ROP administered to the other protocol, CBZ+ROP applied in another study ${ }^{15}$ ) at facial trigger-points each 7 days of treatment (days 0, 7, 14, 21, and 28), during 4 weeks. The usual effective CBZ dosage ranges from 400 to $1000 \mathrm{mg} /$ day. ${ }^{38}$ Since these patients arrived at the Fafe Pain Unit from other Health Institutions with uncontrolled pain (day 0), their CBZ dose (whatever it was) was increased by $200 \mathrm{mg}$ /day; thus, no CBZ titration was performed. Each 7 days, during their visit to the Unit, the NRS score of the patients was recorded and CBZ dose adjusted if necessary. For statistical purposes patients were evaluated at day 0 (arrival to the pain unit) and after a follow-up of 5 months after the end of the 4-week treatment (month 6).

GBP+ROP protocol - Treatment using oral GBP plus administration of a superficial analgesic block with ROP to facial trigger-points, as described elsewhere. ${ }^{3}$ The peripheral block with ROP was performed at the Pain Unit under sterile conditions, using a 27 -gauge needle for administering subcutaneously $2 \mathrm{~mL}$ of a $2 \mathrm{mg} / \mathrm{mL}$ ROP solution. ${ }^{3,39}$ Each local block was peformed once a week ${ }^{3,40}$ during the 1-month therapy (days 0, 7, 14, 21, and 28, when the patient was received by the Unit staff). At day 0, an ROP block was performed and $100 \mathrm{mg}$ GBP administered at night

Table I Baseline characteristics of the patients

\begin{tabular}{|c|c|c|c|}
\hline & $\begin{array}{l}\text { Protocol GBP+ROP } \\
(n=17)\end{array}$ & $\begin{array}{l}\text { Protocol CBZ } \\
(n=23)\end{array}$ & $\begin{array}{l}\text { Protocol MVD surgery } \\
(n=22)\end{array}$ \\
\hline Age (years, average and SD) & $63(16.3)$ & $66(10.8)$ & $66(9.3)$ \\
\hline Gender (women/total) & $12 / 17$ & $19 / 23$ & $15 / 22$ \\
\hline \multicolumn{4}{|c|}{ Pain location (trigeminal branches) } \\
\hline VI or V2 or V3 & 7 & 13 & 6 \\
\hline $\mathrm{V} 1+\mathrm{V} 2$ or $\mathrm{V} 2+\mathrm{V} 3$ & 6 & 7 & 9 \\
\hline $\mathrm{VI}+\mathrm{V} 2+\mathrm{V} 3$ & 4 & 3 & 7 \\
\hline Facial side (right/total) & $12 / 17$ & $10 / 23$ & $11 / 22$ \\
\hline \multicolumn{4}{|l|}{ Pain duration at day 0} \\
\hline I-5 years & 13 & 9 & 4 \\
\hline $6-10$ years & 4 & 5 & 14 \\
\hline$\geq I I$ years & 0 & 9 & 4 \\
\hline
\end{tabular}

Abbreviations: GBP+ROP, gabapentin+ropivacaine; $C B Z$, carbamazepine; MVD, microvascular decompression. 
to each patient. On subsequent days, daily GBP increase followed the rationale described in Lemos et al. ${ }^{3}$ For statistical purposes patients were evaluated at day 0 (arrival to the pain unit) and after a follow-up of 5 months (month 6).

MVD protocol - This technique is thoroughly described elsewhere. ${ }^{37}$ During pre-surgery, MVD patients undergo tests (blood, electrocardiogram, chest X-ray, computed tomography (CT scan)) several days before surgery. During surgery, patients are anesthetized always using the same protocol (endovenous general anesthesia) and are positioned on their back with their head turned or on their side with the symptomatic side facing up. A vertical incision is made behind the ear, 3-5 mm medial to the mastoid notch and extending about the length of the ear. A circular portion of the skull is removed exposing the underlying dura, which is opened to expose the cerebellum and reach the posterior fossa. The cerebellum is allowed to fall out of the way exposing the side of the brainstem. By advancing over the superior surface of the cerebellum, the VII and VIII cranial nerves are avoided. The arachnoid membrane is dissected allowing visualization of the VII, VIII, and finally the trigeminal nerve. The offending loop of blood vessel is then mobilized. Venous vessels above or below the nerve are dissected away from the nerve and are coagulated and divided if needed. A sponge-like material (Teflon) is inserted between the vessel in contact with the nerve (usually the superior cerebellar artery). ${ }^{41}$ Frequently a groove or indentation is seen in the nerve where the offending vessel was in contact with the nerve. The sponge-like material is placed between the nerve and the offending blood vessel to prevent the vessel from returning to its native position. If venous vessels alone are in contact with the nerve, no prosthesis is required as they are coagulated and divided. ${ }^{37}$ After the decompression is complete, the wound is flushed clean with saline solution. The dura is sewn closed. The skull is reconstructed and the overlying tissues are closed in multiple layers. The patient is allowed to wake up and is taken to an intensive care unit or other close observation unit for 3-5 days before returning home. For statistical purposes patients were evaluated at day 0 (day before surgery) and after a follow-up of 6 months (month 6).

\section{Clinical outcome}

The predefined outcome measures were:

1. Evaluation of pain intensity using the NRS scale. Evaluation points were the following: at the arrival at the Pain Unit (CBZ and GBP+ROP protocols) or the day before surgery at the Neurosurgical Department (MVD protocol) (day 0) and 6 months later (month 6).
Patients were told to locate their relative pain in a line marked with numbers, from 0 (no pain) in the extremity on the left to 10 (the worst pain imaginable) in the extremity on the right. Moderate pain was considered to be $>3(\mathrm{NRS}>3)$ and severe pain $>6(\mathrm{NRS}>6) .{ }^{42}$ A pain reduction of 2 points in the 11-point NRS scale from the baseline pain score (day 0) was considered to be clinically significant. ${ }^{43-45}$

2. Daily number or paroxysmal pain episodes. Although this variable was evaluated every day, only data obtained at day 0 and month 6 were used for statistical analysis.

3. Adverse side effects, especially those involving sensory alterations. For each patient of the protocols evaluated, the types of sensory deficits were recorded before (day 0 ) and 6 months after the beginning of therapeutical intervention.

4. The Hospital Anxiety and Depression Scale (HADS) questionnaire $^{46,47}$ is a self-screening evaluation for depression and anxiety. It consists of 14 questions, 7 for anxiety and 7 for depression, which were presented to patients of the three protocols at day 0 and month 6 .

5. Evaluation of life quality using the Sickness Impact Profile (SIP). ${ }^{48-50}$ This questionnaire, adapted to the Portuguese population, ${ }^{49}$ evaluated the evolution of the quality of life of patients submitted to the three protocols, from day 0 to month 6 . SIP evaluates the descriptive profile of patients in terms of impact of the pathology analyzed upon specific daily life behaviors. We analyzed the answers obtained at day 0 and month 6 to 136 questions distributed along the following categories: "Domestic Work", "Mobility", “Communication", "Locomotion", "Eating", "Recreation-Pastimes", "Emotion", "Social Interaction", "Alertness", and "Rest".

6. Questionnaire on the satisfaction with the treatment and medical team (QUASU). It contains 47 items that evaluate patient satisfaction at different levels: Access, Expenses, Technical Quality, Communication/Information, Interpersonal Relations, Team Coordination, and Global Evaluation (created by McIntyre et $\mathrm{al}^{51}$ based on the Portuguese population).

The follow-up evaluation was performed at the end of the day, on completion of month 6 , during a phone interview to each patient. For NRS evaluation the patient was asked to reveal (1) the pain felt at that moment as a number on the NRS scale with which they were used to dealing with or, in case of no pain, (2) which was the pain felt in the worst day of the last week before the interview. For the number of pain crisis, each patient was asked (3) how many pain attacks they had suffered 
during that day or, in case of no pain, (4) how many pain crises they had suffered in the worst day of the last week before the interview. If no pain was recorded following these four questions, the staff recorded 0 (zero) pain crisis for the patient. The adverse side effects were also recorded and patients completed the SIP and HADS questionnaires.

\section{Direct cost analysis: pharmacological and hospital costs}

For patients submitted to pharmacological (CBZ and GBP+ROP protocols) or surgical (MVD protocol) therapies, direct medical cost estimates were determined using hospital cost accounting data published in Diário da República, the "Simposium Terapêutico 2008", and the price lists included in the latter. ${ }^{52,53}$ Medical costs were calculated using the patientreported dosage and number of doses taken daily and Hospital internment, which were converted to the cost between day 0 and 1 month (according to the 4-week treatment in protocols GBP+ROP and CBZ) and between month 1 and month 6 (follow-up for the three protocols) (Table 2).

\section{Statistics}

Data are presented as mean \pm standard deviation (SD) along the several variables under study. The normal distribution of the results was verified using the Kolmogorov-Smirnov

Table 2 Average direct healthcare cost per patient

\begin{tabular}{|c|c|c|c|}
\hline Protocol & Cost category & $\begin{array}{l}\text { Ist } \\
\text { month }(€)\end{array}$ & $\begin{array}{l}\text { 2nd-6th } \\
\text { month }(€)^{*}\end{array}$ \\
\hline \multirow[t]{7}{*}{ GBP+ROP } & GBP & 7.29 & 109.2 \\
\hline & Ist consultation & 71.42 & \\
\hline & Other consultations & & 205.1 \\
\hline & 3 sessions & 75.81 & \\
\hline & Imaging tests & 79.55 & \\
\hline & Laboratory tests & 18.40 & \\
\hline & Total & $252.47(0)$ & $3 \mid 4.3(0)$ \\
\hline \multirow[t]{6}{*}{ CBZ } & $\mathrm{CBZ}$ & 9.9 & 49.9 \\
\hline & Ist consultation & 71.42 & \\
\hline & Other consultations & 205.10 & 205.1 \\
\hline & Imaging tests & 79.55 & \\
\hline & Laboratory tests & 18.40 & \\
\hline & Total & $384.2(1.5)$ & $255.0(6.3)$ \\
\hline \multirow[t]{7}{*}{ MVD } & $\mathrm{CBZ}+\mathrm{GBP}$ & 30.39 & 49.6 \\
\hline & Surgery & 719.90 & \\
\hline & Ist consultation & 71.42 & \\
\hline & Other consultations & 137.12 & 205.1 \\
\hline & Imaging tests & 79.55 & \\
\hline & Laboratory tests & & \\
\hline & Total & $1056.78(22.3)$ & $254.7(40.9)$ \\
\hline
\end{tabular}

Notes: *Sum of costs over 5 months (months $2-6$ ); values in parentheses = standard deviation.

Abbreviations: GBP+ROP, gabapentin+ropivacaine; CBZ, carbamazepine; MVD, microvascular decompression. test, whereas the equality of variances was evaluated by the Levene test. A logarithmic transformation of data has been used whenever the homogeneity of variances was not verified. Mean NRS scores, number of pain crisis, direct costs, SIP, and HADS values at day 0 and month 6 (or only at month 6 for costs data) were compared using paired-samples Student's $t$-test whenever possible, or the one-sample $t$-test when one of the means showed absence of variation (see Results section). Mean NRS scores following protocols CBZ, GBP+ROP, and MVD were compared at month 6 using a one-way analysis of variance (ANOVA) followed by the Tukey post hoc test.

\section{Results}

\section{Patient baseline characteristics}

The baseline data for the demographic characteristics of patients selected for the three protocols are shown in Table 1.

\section{Effect of CBZ, GBP+ROP and MVD protocols in pain control}

No differences in pain intensity were found between patients from GBP+ROP protocol $\left(\mathrm{NRS}_{\mathrm{d} 0}=8.8 \pm 1.4\right)$ and $\mathrm{CBZ}$ protocol $\left(\mathrm{NRS}_{\mathrm{d} 0}=9.1 \pm 1.4\right)(P=0.41, t$-test $)($ Figure 1$)$ at the beginning of the treatment [day $0(\mathrm{~d} 0)$ ], whereas 21 of 22 MVD patients presented an NRS score of 10, the most painful condition imaginable $\left(\mathrm{NRS}_{\mathrm{d} 0}=9.9 \pm 0.4\right)$. Five months after the 4-week treatment followed in CBZ and

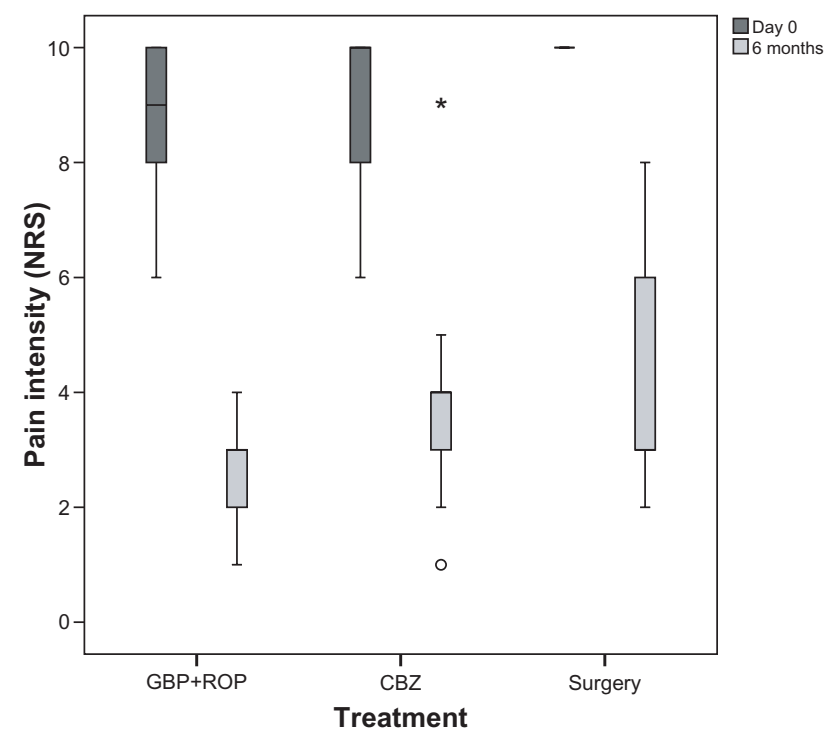

Figure I Effect of the three protocols (GBP+ROP, CBZ, and MVD) on the pain intensity of patients 6 months after day 0 . For significant differences see the Results section.

Abbreviations: $G B P+R O P$, gabapentin+ropivacaine; $C B Z$, carbamazepine; MVD, microvascular decompression; NRS, National Rating Scale. 
GBP+ROP protocols [month $6(6 \mathrm{~m})$, both pharmacological approaches had decreased significantly, pain measured by NRS scores $\left(\mathrm{GBP}+\mathrm{ROP}_{\mathrm{d} 0} \times \mathrm{GBP}+\mathrm{ROP}_{6 \mathrm{~m}}, P<0.0001\right.$; $\mathrm{CBZ}_{0} \times \mathrm{CBZ}_{6 \mathrm{~m}}, P<0.0001$, paired-samples $t$-tests), while 6 months after MVD surgery NRS scores were also significantly reduced $\left(\mathrm{MDV}_{\mathrm{d} 0} \times \mathrm{MDV}_{6 \mathrm{~m}}, P<0.001\right.$, one-sample $t$-test). Although the three protocols reduced pain intensity, GBP+ROP therapy resulted in a significantly lower NRS score than patients following CBZ or MVD protocols $\left(\mathrm{GBP}+\mathrm{ROP}, \mathrm{NRS}_{6 \mathrm{~m}}=2.6 \pm 1.00 ; \mathrm{CBZ}, \mathrm{NRS}_{6 \mathrm{~m}}=3.9 \pm 1.5\right.$; MVD, $\mathrm{NRS}_{6 \mathrm{~m}}=4.2 \pm 1.7$, one-way ANOVA, $P=0.002$; $\mathrm{GBP}+\mathrm{ROP}_{6 \mathrm{~m}} \times \mathrm{CBZ}_{6 \mathrm{~m}}, P=0.011, \mathrm{GBP}+\mathrm{ROP}_{6 \mathrm{~m}} \times \mathrm{MVD}_{6 \mathrm{~m}}$, $P=0.002$, Tukey tests) (Figure 1). With respect to the NRS observed at month 6 for MVD patients, it can be concluded by a one-sample $t$-test that the NRS value is significantly different from $10(P<0.001)$, the value observed before surgery (day 0$)$.

The baseline number of daily crises of paroxysmal sudden and intense pain was similar between patients of both pharmacological protocols (day 0: GBP+ROP, $n_{\text {crises }}=9.6 \pm 1.5$; $\mathrm{CBZ}, \mathrm{n}_{\text {crises }}=10.7 \pm 2.2 ; P=0.114, t$-test $)$, whereas 21 of 22 MVD patients presented 12 pain crises per day (MVD, $\mathrm{n}_{\text {crisis }}=11.8 \pm 0.6$ ) (Figure 2). Five months after the 4-week treatment followed in CBZ and GBP+ROP protocols (month 6), all three protocols had decreased significantly the number of daily pain crises (month 6: GBZ+ROP, $\mathrm{n}_{\text {crises }}=2.0 \pm 1.6 ; \mathrm{CBZ}, \mathrm{n}_{\text {crises }}$ $=4.1 \pm 1.7 ; \mathrm{MVD}, \mathrm{n}_{\text {crisis }}=2.6 \pm 0.6-\mathrm{GBP}+\mathrm{ROP}_{\mathrm{d} 0} \times \mathrm{GBP}+\mathrm{ROP}_{6 \mathrm{~m}}$, $P<0.0001 ; \mathrm{CBZ}_{\mathrm{d} 0} \times \mathrm{CBZ}_{6 \mathrm{~m}}, P<0.0001$, paired samples $t$-tests; $\mathrm{MDV}_{\mathrm{d} 0} \times \mathrm{MDV}_{6 \mathrm{~m}}, P<0.001$, one-sample $t$-test)

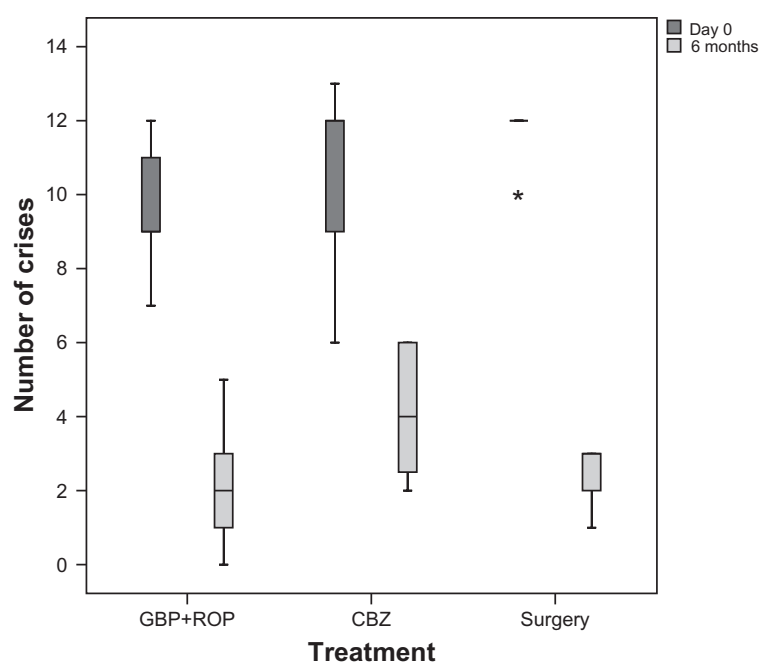

Figure 2 Effect of the three protocols (GBP+ROP, CBZ, and MVD) on number of daily episodes of pain before (day 0 ) and after a 5-month follow-up (month 6). For significant differences see the Results section.

Abbreviations: GBP+ROP, gabapentin+ropivacaine; $C B Z$, carbamazepine; MVD, microvascular decompression.
(Figure 2). Again, with respect to the number of daily pain crises observed at month 6 in MVD patients, it can be concluded by a one-sample $t$-test that the number of crises is significantly different from $12(P<0.001)$, the value observed before surgery (day 0 ).

\section{Daily dose of anticonvulsants}

The three protocols showed a different evolution in the consumption of anticonvulsants CBZ or GBP. At day 0 and 1 $\mathrm{GBP}+\mathrm{ROP}$ patients took $100 \mathrm{mg}$ /day of GBP; at day 7, these patients were taking 200 or $300 \mathrm{mg} /$ day (mean $=266,67 \mathrm{mg} /$ day); at the end of the 4-week treatment patients were taking $300 \mathrm{mg}$ /day of GBP, which was maintained during the next 5 months, until month $6 .^{3}$ Patients following CBZ protocol arrived to the Hospital and began taking $626 \pm 163 \mathrm{mg} / \mathrm{day}$ of CBZ; at the end of the 4-week treatment, CBZ intake increased to $757 \pm 200 \mathrm{mg} / \mathrm{day}$, which was increased even at month 6 to $826 \pm 291 \mathrm{mg} /$ day. ${ }^{15}$ Finally, MVD protocol patients were taking $600 \mathrm{mg} /$ day of CBZ in monotherapy (12 of the 22 patients) or GBP+ROP $(600+600 \mathrm{mg} /$ day $)$; at the end of the follow-up (month 6), MVD patients were still assisted by drugs, although at lower doses, namely $200 \mathrm{mg}$ / day of CBZ or $300 \mathrm{mg} /$ day of GBP, both in monotherapy.

\section{Adverse side effects}

The GBP+ROP protocol resulted in no significant side effects and no sensory deficits. ${ }^{3}$ Patients following the CBZ protocol showed no sensory deficits, but 7 of the 21 patients presented adverse side effects (dizziness). ${ }^{15}$ On the contrary, 5 of the 22 patients submitted to MVD protocol presented hypesthesia of the hemiface affected, 3 were anesthetized in the hemiface, 1 showed paresthesias, and 1 patient died in the immediate postoperative period due to brain hemorrhage, with a total of 10 in 22 patients with sensory sequelae; additionally, 5 of the 22 patients presented dizziness as an adverse side effect and 7 in 22 showed a complete absence of side effects or sequelae.

\section{Direct costs}

Data on direct costs of resources consumption show that MVD full cost was $€ 1056.78 \pm 22.5$ per patient while, on the contrary, CBZ $(€ 384.2 \pm 1.5)$ and especially GBP+ROP (€252.47) were far less expensive between day 0 (before treatment/surgery) and the end of the first month $\left(\mathrm{GBP}+\mathrm{ROP}_{\text {euro }} \times \mathrm{CBZ}_{\text {euro }}, P<0.0001\right.$; $\mathrm{GBP}+\mathrm{ROP}_{\text {euro }} \times \mathrm{MVD}_{\text {euro }}, P<0.0001$, one-sample $t$-tests; $\mathrm{CBZ}_{\text {euro }} \times \mathrm{MVD}_{\text {euro }}, P<0.0001$, paired-samples $t$-test) (Table 2). It can be concluded by one-sample $t$-tests that 
the total direct cost during the first month per patient submitted to CBZ or MVD protocols is significantly different from $€ 252.47$ ( $P<0.001$ ), the average total cost value observed for each GBP+ROP patient. The difference is mostly explained by 2 factors: the cost of the surgical procedure and the cost of hospital stay for MVD patients. However, during months $2-5$, the financial situation alters: GBP+ROP protocol becomes the most expensive treatment $\left(\mathrm{GBP}+\mathrm{ROP}_{\text {months 2-6 }}=€ 314.3\right)$, as GBP is more expensive than $\mathrm{CBZ}\left(\mathrm{CBZ}_{\text {months 2-6 }}=€ 255.0 \pm 6.3\right)$ and MVD patients take a low dosage of anticonvulsants $\left(\mathrm{MVD}_{\text {months } 2-6}=€ 254.7 \pm 40.9\right)$ (Table 2).

\section{Functional quality of life and patient satisfaction}

Quality of life measured by the scores obtained through the SIP questionnaire for patients in both GBP+ROP and CBZ protocols showed a significant improvement in functionality $\left(\mathrm{GBP}+\mathrm{ROP}_{\mathrm{d} 0} \times \mathrm{GBP}+\mathrm{ROP}_{6 \mathrm{~m}}, P<0.0001\right)$, which was not achieved at a significant level by MVD patients $\left(\mathrm{MVD}_{\mathrm{d} 0} \times \mathrm{MVD}_{6 \mathrm{~m}}\right.$, $P=0.086$, paired-samples $t$-tests) (Figure 3A). Interestingly, however, both anxiety and depression scores were significantly improved in MVD patients from day 0 to month 6 , as measured by HADS questionnaire $\left(\mathrm{MVD}_{\mathrm{ANXd} 0} \times \mathrm{MVD}_{\mathrm{ANX} 6 \mathrm{~m}}\right.$, $P<0.001 ; \mathrm{MVD}_{\mathrm{DEPd} 0} \times \mathrm{MVD}_{\mathrm{DEP} 6 \mathrm{~m}}, P<0.0001$, pairedsamples $t$-test) (Figures 3B and 3C), whereas CBZ patients showed a significant improvement only in anxiety scores $\left(\mathrm{CBZ}_{\mathrm{ANXd} 0} \times \mathrm{CBZ}_{\mathrm{ANX} 6 \mathrm{~m}}, P=0.036\right.$, paired-samples $t$-test $)$ and $\mathrm{GBP}+\mathrm{ROP}$ patients did not improve in any of the dimensions evaluated by the HADS questionnaire (Figures $3 \mathrm{~B}$ and $3 \mathrm{C}$ ).

The satisfaction of the patients with the treatment and with the clinical team, measured by the QUASU questionnaire, revealed a complete or high level of satisfaction of patients (Figure 4). While all patients allocated to protocols GBP+ROP and CBZ were totally satisfied with the treatment and clinical team, 5 out of 22 MVD patients were acceptably satisfied or unsatisfied with the treatment (Figure 4A) due to sensory adverse side effects, and 2/22 MVD patients were just acceptably satisfied with the team (Figure 4B).

\section{Discussion}

Economic evaluation of different therapeutical approaches is intended to support health-related decision-making by informing clinical decision-makers of estimates of costs and benefits of surgery and comparing them with the prevalent pharmacological intervention. Although the three branches of the present study were randomly obtained at 3 different times, the clinical outcomes obtained and the direct costs associated
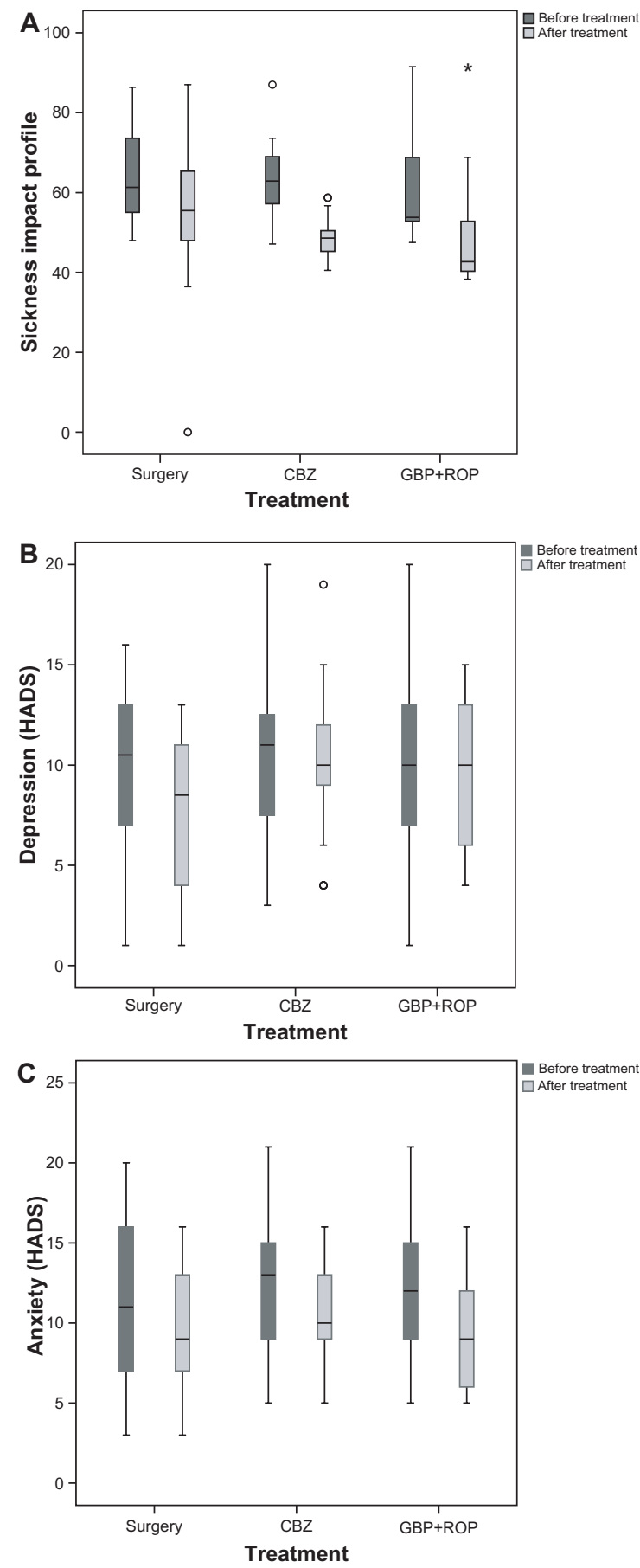

Figure 3 Effect of GBP+ROP, CBZ, and MVD protocols on the total SIP score of quality of life $(\mathbf{A})$ and on the anxiety $(\mathbf{B})$ and depression $(\mathbf{C})$ scores measured by the HADS questionnaire. For significant differences see the Results section.

Abbreviations: GBP+ROP, gabapentin+ropivacaine; $C B Z$, carbamazepine; MVD, microvascular decompression; HADS, Hospital Anxiety and Depression Scale; SIP, Sickness Impact Profile.

reinforce the necessity of careful evaluation of the patient before the decision to make an invasive surgical intervention. All protocols, GBP+ROP, CBZ, and MVD, decreased pain behavior significantly in TN patients, as measured by the NRS scale and number of daily pain crises, and total or a high 


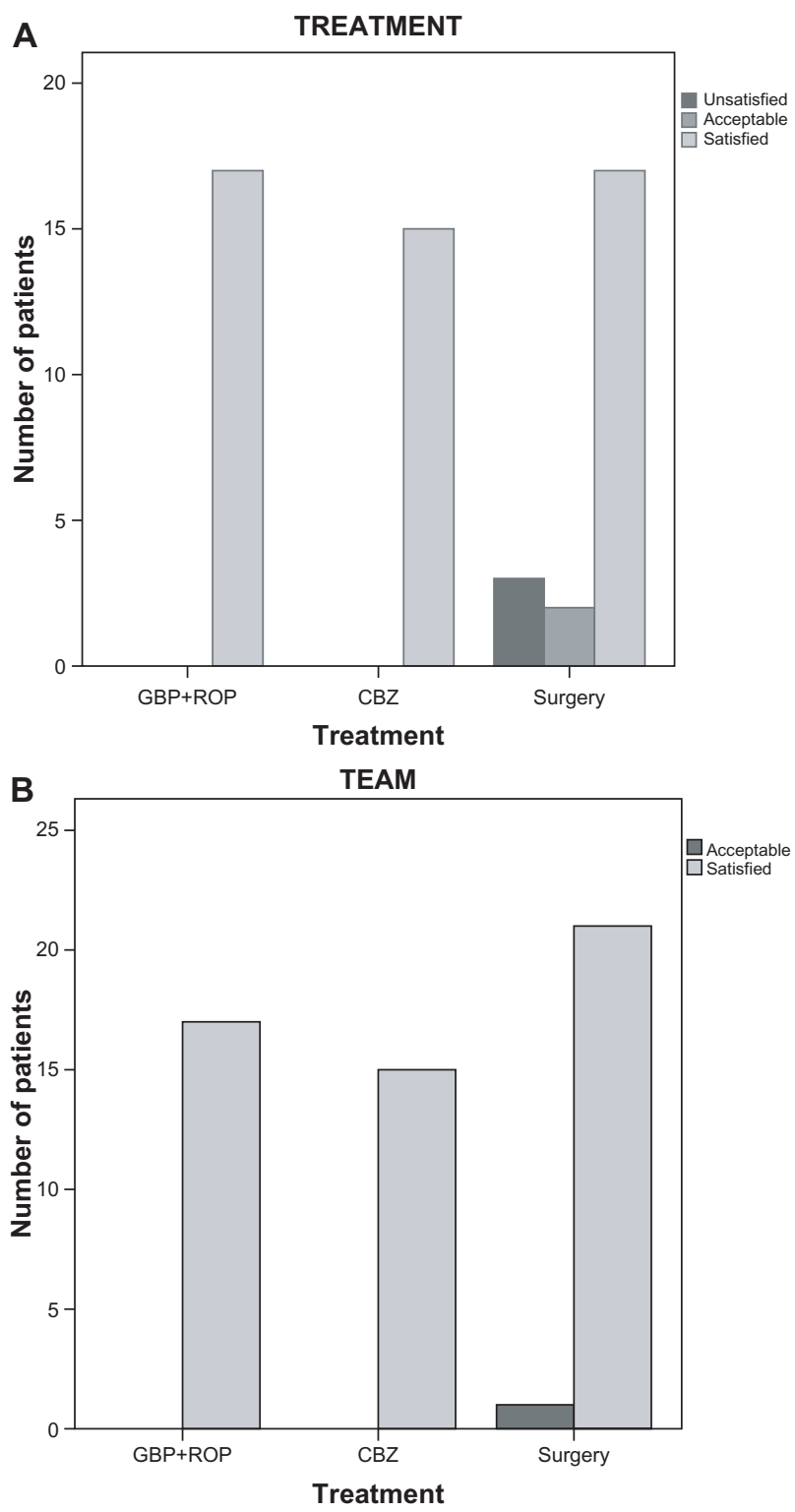

Figure 4 Satisfaction of patients submitted to GBP+ROP, $C B Z$, and MVD, for treatment $(\mathbf{A})$ and the clinical team (B).

Abbreviations: GBP+ROP, gabapentin+ropivacaine; CBZ, carbamazepine; MVD, microvascular decompression.

satisfaction with both the treatment and clinical team was achieved. However, the degree of adverse side effects was different between protocols, GBP+ROP showing no side effects and MVD presenting several facial sensorial deficits, with different levels of severity. Additionally, during the first month of treatment, a much higher cost was attributed to MDV protocol due to surgical procedures, hospital stay, and maintenance of drug therapy, whereas pharmacotherapy costs were mainly drug costs. On the contrary, during the follow-up the surgical protocol was the less costly protocol and GBP+ROP was the most expensive, indicating that in longer follow-ups the MVD is less expensive than a prolonged drug treatment.

\section{Methodological considerations}

The rationale of the present study was to compare the efficacy of different therapeutical approaches to TN and evaluate the direct costs associated with each one. The GBP+ROP protocol was chosen due to its improved efficacy as an association of an anticonvulsant and the analgesic block of TN trigger-points, ${ }^{3}$ which can constitute a valid alternative whenever the classic first-choice pharmacological treatment, CBZ in monotherapy, ${ }^{1}$ cannot be used. The CBZ protocol is still considered the first-line choice for TN treatment. ${ }^{1,54-56}$ In order to eliminate the possibility that any beneficial effect could depend on the physical action of local administration of the analgesic ROP solution by clearing adhesions or inflammatory molecules from the vicinity of the nerve, ${ }^{40}$ the CBZ protocol was accompanied by injection of saline to TN trigger-points. Thus, the improvements observed in the different outcomes analyzed resulted exclusively from the pharmacological action of GBP+ROP and CBZ and not from the manipulation and liquid introduction at trigger-points., ${ }^{3,15}$ The frequency of ROP analgesic block applied subcutaneously to TN patients followed the practice guidelines for the interventional techniques: ${ }^{40}$ a patient received an injection at intervals of no less than 1 week, which was the period chosen to mediate between each ROP (or saline) administration. The MVD protocol is still considered the first-line surgical treatment for medically unresponsive $\mathrm{TN},{ }^{57-59}$ mainly in younger patients, ${ }^{28}$ although radiosurgery is the main option in radiosurgery centers, especially when applied in older people. ${ }^{28}$

\section{Clinical impact of the three TN treatment protocols}

Since a 2-point decrease in the mean NRS scale $(0-10$ scale $)$ is considered the minimum clinical relevant difference in pain intensity when comparing the effect of 2 treatments, ${ }^{43-45}$ the GBP+ROP, CBZ, and MVD protocols, by decreasing pain intensity in $6.1,5.3$, and 5.7 (respectively) points, were clinically effective in reducing pain at month 6; additionally, all protocols also reduced significantly the number of daily pain crises. These results are in accordance with the literature in terms of efficacy in controlling pain in TN. ${ }^{3,15,37}$ Since this study is a retrospective and observational evaluation of 3 sets of patients who were randomly allocated in 3 different studies, the degrees of reduction of pain values cannot be compared among protocols (both NRS scale values and number of daily pain crises). Another study has compared outcomes 
in a group of patients who have had both pharmacological and surgical TN treatments. Patients treated with oxcarbazepine and different surgeries (MVD and Gasser ganglion surgery) were compared and patients would prefer to have had surgery before. ${ }^{60}$ Although sensory deficits and necessity for repeating surgery have occurred, pain relief was significantly longer after surgery than after pharmacological treatment, recurrence being 10 months after oxcarbazepine and 28 months after surgery. As these data cannot be extrapolated to other anticonvulsivant drugs, similar comparative studies should be performed in the future.

When comparing the effect of GBP+ROP, CBZ and MVD protocols between baseline (day 0) and month 6, other indications of the clinical outcome can be performed using specific questionnaires. The functional analysis of quality of life measured by the SIP indicated that functional improvement was significant after pharmacological protocols but not after MVD. This may result from the several patients with sensory deficits occurring after the latter, which may counteract the functional improvement resulting from pain control. This study shows that, in addition to $\mathrm{GBP}+\mathrm{ROP}$ protocol, ${ }^{3} \mathrm{CBZ}$ improves functionality. Only 1 paper has evaluated SIP in a surgical context, ${ }^{61}$ indicating improvement in TN patients after epidural motor cortex stimulation. HADS showed that only patients submitted to MVD showed a significant improvement in both anxiety and depression scores, probably because patients who are hospitalized for surgery have a very high degree of anxiety and expectation. ${ }^{62}$ On the contrary, all GBP+ROP and CBZ patients were completely satisfied with the treatment protocol and the clinical team, whereas some MVD patients were unsatisfied or acceptably satisfied with the treatment protocol; this may result from the sequelae that were present in a significant number of MVD patients. Finally, CBZ protocol resulted in dizziness only in some patients and GBP+ROP patients showed virtually no adverse side effects.

Another important therapeutical improvement of GBP+ROP and MVD protocols is the demonstration of a large decrease in the daily dose of anticonvulsivant drug intake from baseline (day 0), both at the end of the treatment (day 29, GBP+ROP protocol) and, even further, after the 5-month follow-up (month 6). ${ }^{3}$ On the contrary, in CBZ monotherapy a progressive increase was observed in daily CBZ dosage. ${ }^{15}$ These data show that the clinical results of NT treatment with GBP+ROP and MVD are superior to those for $\mathrm{CBZ}$ monotherapy, because the significantly lower dose of drugs used strongly decreased the presence/intensity of adverse side effects.

\section{Direct costs}

The data presented in this study point to a much higher cost of the surgical approach to TN treatment than the other two pharmacological protocols. This results directly from the high costs of surgical intervention and hospital stay before, during, and after the MVD. However, during follow-up, the maintenance of pain control in TN patients submitted to surgery requires less medical therapy than the other two protocols. Although being clearly the less expensive treatment during the first 4-week treatment period, the GBP+ROP protocol tends to be the most expensive therapy after stabilization of TN pain control (follow-up) due to the higher cost of GBP drug (Neurontin ${ }^{\circledR}$ [Pfizer Laboratories, Porto Salvo, Portugal] or Gabamox ${ }^{\circledR}$ [Pentafarma, Prior Velho, Portugal]) versus CBZ drug (Tegretol ${ }^{\circledR}$ [Novartis Farma, Sintra, Portugal]). Data suggest that larger follow-up periods may reveal that the MVD approach is less expensive than the drug therapies. Only a few studies have evaluated the effects of drugs in the reduction of costs in $\mathrm{TN},{ }^{34}$ or have compared the cost of different TN surgical protocols. ${ }^{32,33}$ In accordance with a less expensive experience resulting from MVD surgery, in a comparison between this surgery, glycerol rhizotomy, and stereotactic radiosurgery, it was shown that in longer follow-up intervals MVD is predicted to be the most cost-effective surgery and should be considered the preferred operation for patients. ${ }^{32}$ However, recent data point to cyberknife radiosurgery being a cost-saving alternative to MVD. ${ }^{33}$ The only study showing cost-saving using drug therapy in TN point to the use of pregabalin. ${ }^{34}$ Finally, to the best of our knowledge, the present paper is the first attempt to compare clinical outcomes and costs among pharmacological protocols and the most common surgical approach in TN (excluding radiosurgery centers).

\section{Limitations of the study}

This study has some limitations. First, the rates of pain improvement in the three groups of patients are not directly comparable; although they were randomly selected, patients allocated to the $\mathrm{CBZ}$ and $\mathrm{GBP}+\mathrm{ROP}$ branches were recruited from 2 different studies ${ }^{3,15}$ and only the MVD patients were retrospectively selected for this specific study. Second, patients from MVD protocol had pain scores in the NRS scales significantly higher at baseline (day 0) than patients from $\mathrm{CBZ}$ and $\mathrm{GBP}+\mathrm{ROP}$ protocols; the difference 
in patients' characteristics is explained by the fact that MVD is usually not seen as an alternative to pharmacological protocols but, rather, as a second-line strategy whenever first-line or second-line drugs cause intolerable side effects or cannot control TN pain. Accordingly, the group of MVD patients had already failed the pharmacological therapy and thus had also longer pain periods than the patients from the other two protocols. Third, the complication rate of MVD patients may be higher than that in other published series, which is likely to be due to the small number of patients included in the study. Fourth, the cost analysis does not include costs associated with loss of productivity by patients during the admission and evaluation periods at the Hospital/ Pain Unit and insurance contributions (indirect costs). Fifth, although the pain intensity and number of paroxysmal crises were significantly improved after 6 months of treatment with CBZ+ROP, CBZ, and MVD protocols, the follow-up period may not have been sufficient to determine the potential long-term effects of the treatments. Consequently, studies with larger numbers of patients, sequential allocation of patients for surgical and pharmacological branches, and longer follow-up periods should be undertaken to verify data obtained in the present study.

\section{Conclusion}

Although CBZ has long been known, and is still recognized, as the first-line drug choice for pain control in TN, an improvement of second-line drug therapy has been achieved by combining GBP intake with the peripheral analgesic block of TN trigger-points by ROP (GBP+ROP). Whenever pharmacological approaches fail, microvascular decompression is a surgical method of choice (MVD). We show that the three protocols resulted in a clinically significant improvement in pain, as shown by the NRS scale and number of paroxysmal pain crises, which were accompanied by a clear decrease in the daily CBZ/GBP dosage needed for TN pain control, with a consequent reduction in associated adverse side effects. The cost analysis indicates that the first 4-week period of treatment (or admission, surgery, and treatment in MVD patients) results in GBP+ROP being by far the least expensive protocol and MVD the most expensive. However, over time (follow-up), GBP+ROP protocol tended to be the most costly treatment and MVD the least expensive (very similar to $\mathrm{CBZ}$ protocol). Longer follow-up periods will potentially indicate that MVD is a less costly approach to TN than the drug treatments.

\section{Acknowledgments}

The authors thank the Clinical Director of the Hospital Center of Alto Ave (Fafe Unit) in 2008 and the Chronic Pain Unit team of the same Hospital for collaboration in this study. This study was supported by Project Nr. PTDC/ SAU-NEU/108557/2008 from Fundação para a Ciência e Tecnologia (FCT) and FEDER.

\section{Disclosure}

No competing financial interests exist. All authors meet the criteria for authorship. We disclose that Armando Almeida and Laurinda Lemos serve as occasional speakers for Grünenthal SA (Portugal). Funding for the editorial support (not for the research) of this article was provided by Grünenthal SA.

\section{References}

1. Cheshire WP. Trigeminal neuralgia: for one nerve a multitude of treatments. Expert Rev Neurother. 2007;7:1565-1579.

2. Tölle T, Dukes E, Sadosky A. Patient burden of trigeminal neuralgia: results from a cross-sectional survey of health state impairment and treatment patterns in six European countries. Pain Pract. 2006;6:153-160.

3. Lemos L, Flores S, Oliveira P, Almeida A. Gabapentin supplemented with Ropivacaine block of trigger-points improves pain control and quality of life in Trigeminal Neuralgia patients when compared with gabapentin alone. Clin J Pain. 2008;24:64-75.

4. Marbach JJ, Lund P. Depression, anhedonia and anxiety in temporomandibular joint and other facial pain syndromes. Pain. 1981;11:73-84.

5. Katusic S, Williams DB, Beard CM, Bergstralh EJ, Kurland LT. Epidemiology and clinical features of idiopathic trigeminal neuralgia and glossopharyngeal neuralgia: similarities and differences, Rochester, Minnesota, 1945-1984. Neuroepidemiology. 1991;10:276-281.

6. MacDonald BK, Cockerell OC, Sander JW, Shorvon SD. The incidence and lifetime prevalence of neurological disorders in a prospective community-based study in the UK. Brain. 2000;123:665-676.

7. Headache Classification Subcommittee of the International Headache Society. The International Classification of Headache Disorders, 2nd Edition. Cephalalgia. 2004;24(Suppl 1):S16-S149.

8. Cheshire WP. Trigeminal neuralgia: a guide to drug choice. CNS Drugs. 1997; 7:98-110.

9. Sindrup SH, Jensen TS. Pharmacotherapy of trigeminal neuralgia. Clin J Pain. 2002;18:22-27.

10. Campbell FG, Graham JG, Zilkha KJ. Clinical trial of carbazepine (tegretol) in trigeminal neuralgia. J Neurol Neurosurg Psychiatry. 1966;29:265-267.

11. Jorns TP, Zakrzewska JM. Evidence-based approach to the medical management of trigeminal neuralgia. Br J Neurosurg. 2007;21:253-261.

12. Cruccu G, Gronseth G,Alksne J, et al.AAN-EFNS guidelines on trigeminal neuralgia management. Eur J Neurol. 2008;15:1013-1028.

13. Zakrzewska JM, Chaudhry Z, Nurmikko TJ, Patton DW, Mullens EL. Lamotrigine (lamictal) in refractory trigeminal neuralgia: results from a double-blind placebo controlled crossover trial. Pain. 1997;73:223-230.

14. Royal M, Wienecke G, Movva V, et al. Open label trial of ox carbamazepine in neuropathic pain. Pain Med. 2001;2:250-151.

15. Lemos L, Fontes R, Flores S, Oliveira P, Almeida A. Effectiveness of the association between carbamazepine and peripheral analgesic block with ropivacaine for the treatment of trigeminal neuralgia. J Pain Res. 2010;3:201-212. 
16. Solaro C, Messmer Uccelli M, Uccelli A, Leandri M, Mancardi GL. Low-dose gabapentin combined with either lamotrigine or carbamazepine can be useful therapies for trigeminal neuralgia in multiple sclerosis. Eur Neurol. 2000;44:45-48.

17. Cheshire WP. Can MRI distinguish injurious from innocuous trigeminal neurovascular contact? J Neurol Neurosurg Psychiatry. 2005a;76:1470-1471.

18. Lang E, Naraghi R, Tanrikulu L, et al. Neurovascular relationship at the trigeminal root entry zone in persistent idiopathic facial pain: findings from MRI 3D visualisation. J Neurol Neurosurg Psychiatry. 2005;76:1506-1509.

19. Pagni CA, Fariselli L, Zeme S. Trigeminal neuralgia. Non-invasive techniques versus microvascular decompression. It is really available any further improvement? Acta Neurochir Suppl. 2008;101 27-33.

20. Cheshire WP. Trigeminal neuralgia: diagnosis and treatment. Curr Neurol Neurosci Rep. 2005b;5:79-85.

21. Barker FG II, Jannetta PJ, Bissonette DJ, et al. The long-term outcome of microvascular decomplression for trigeminal neuralgia. $N$ Engl J Med. 1996;334:1077-1083.

22. Lovely TJ, Jannetta PJ. Microvascular decompression for trigeminal neuralgia. Surgical technique and long-term results. Neurosurg Clin NAm. 1997;8:11-29.

23. Kanpolat Y, Savas A, Bekar A, Berk C. Percutaneous controlled radiofrequency trigeminal rhizotomy for the treatment of idiopathic trigeminal neuralgia: 25-year experience with 1,600 patients. Neurosurgery. 2001;48:524-532.

24. Fountas KN, Lee GP, Smith JR. Outcome of patients undergoing gamma knife stereotactic radiosurgery for medically refractory idiopathic trigeminal neuralgia: Medical College of Georgia's experience. Stereotact Funct Neurosurg. 2006;84:88-96.

25. Dhople AA, Adams JR, Maggio WW, Naqvi SA, Regine WF, Kwok Y. Long-term outcomes of Gamma Knife radiosurgery for classic trigeminal neuralgia: implications of treatment and critical review of the literature. J Neurosurg. 2009;111:351-358.

26. Knafo H, Kenny B, Mathieu D. Trigeminal neuralgia: outcomes after gamma knife radiosurgery. Can J Neurol Sci. 2009;36:78-82.

27. Régis J, Metellus P, Hayashi M, et al. Prospective controlled trial of gamma knife surgery for essential trigeminal neuralgia. J Neurosurg 2006;104:913-924.

28. Kondziolka D, Zorro O, Lobato-Polo J, et al. Gamma knife stereotactic radiosurgery for idiopathic trigeminal neuralgia. J Neurosurg. 2010; 112:758-765.

29. Gorgulho A, De Salles AA, McArthur D, et al. Brainstem and trigeminal nerve changes after radiosurgery for trigeminal pain. Surg Neurol. 2006;66:127-135.

30. Regis J, Arkha Y, Yomo S, et al. Radiosurgery in trigeminal neuralgia: long-term results and influence of operative nuances. Neurochirurgie. 2009;55:213-222.

31. Massager N, Murata N, Tamura M, et al. Influence of nerve radiation dose in the incidence of trigeminal dysfunction after trigeminal neuralgia radiosurgery. Neurosurgery. 2007;60:681-687.

32. Pollock BE, Ecker RD. A prospective cost-effectiveness study of trigeminal neuralgia surgery. Clin J Pain. 2005;21:317-322.

33. Tarricone R, Aguzzi G, Musi F, Fariselli L, Casasco A. Cost-effectiveness analysis for trigeminal neuralgia: Cyberknife vs microvascular decompression. Neuropsychiatr Dis Treat. 2008;4:647-652.

34. Pérez C, Saldaña MT, Navarro A, Martínez S, Rejas J. Trigeminal neuralgia treated with pregabalin in family medicine settings: its effect on pain alleviation and cost reduction. J Clin Pharmacol. 2009;49: 582-590.

35. Navarro A, Saldana MT, Pérez C, Torrades S, Rajas J. A costconsequences analysis of the effect of pregabalin in the treatment of peripheral neuropathic pain in routine medical practice in primary care settings. BMC Neurol. 2001;11(1):7(2011).
36. Zakrzewska JM. Trigeminal, eye, and ear pain. In: Melzack R, Wall PD, editors. Handbook of Pain Management - a clinical companion to Wall and Melzack's Textbook of Pain. London: Churchill Livingstone; 2003:199-215

37. Lonser RR, Apfelbaum. Neurovascular decompression in surgical disorders of cranial nerves V, VII, IX, and X. In: Schmidek HH, Roberts DW, editors. Schmidek and Sweet's Operative Neurosurgical Techniques: Indications, Methods, and Results, 5th ed, Vol 2. Philadelphia: Saunders/ Elsevier; 2002:1531-1543.

38. Ahmad M, Goucke CR. Management strategies for the treatment of neuropathic pain in the elderly. Drugs Aging. 2002;19:929-945.

39. Breivik H. Local anesthetic blocks and epidurals In: McMahon SB, Koltzenburg M, editors. Melzack's Textbook of Pain, 5th ed. London: Elsevier-Churchill Livingstone; 2006:903-925.

40. Manchikanti L, Singh V, Trescot AM, Deer TR, Boswell MV. Guidelines for the Practice of Interventional Techniques. In: Boswell MV, Cole BE, editors. Weiner's Pain Management: a practical guide for clinicians, 7th ed. London: CRS Press; 2006:847-878.

41. Lorenzoni J, David P, Devriendt D, et al. Patterns of neurovascular compression in patients with classic trigeminal neuralgia: a highresolution MRI-based study. Eur J Radiol. 2009;doi:10.1016/j. ejrad.2009.09.017.

42. Collins SL, Moore RA, McQuay HJ. The visual analogue pain intensity scale: what is moderate pain in millimeters? Pain. 1997;72:95-97.

43. Farrar JT, Portenoy RK, Berlin JA, Kinman JL, Strom BL. Defining the clinically important difference in pain outcome measures. Pain. 2000;88:287-294.

44. Finnerup NB, Sindrup SH, Bach FW, Johannesen IL, Jensen TS. Lamotrigine in spinal cord injury pain: a randomized controlled trial. Pain. 2002;96:375-383.

45. Salaffi F, Stancati A, Silvestri CA, Ciapetti A, Grassi W. Minimal clinically important changes in chronic musculoskeletal pain intensity measured on a numerical rating scale. Eur J Pain. 2004;8:283-291.

46. Zigmond AS, Snaith RP. The hospital anxiety and depression scale. Acta Psychiatr Scand. 1983;67:361-370.

47. Bjelland I, Dahl AA, Haug TT, Neckelmann D. The validity of the Hospital Anxiety and Depression Scale. an updated literature review. J Psychosom Res. 2002;52:69-77.

48. Bergner M, Bobbitt RA, Carter WB, et al. The sickness impact profile: development and final revision of a health status measure. Med Care. 1981;19:787-805.

49. Turner JA, Romano JM. Psychological and psychosocial evaluation. In: Loeser JD, Butler SH, Chapman CR, Turk DC, editors. "Bonica's Management of Pain", 3rd ed. Philadelphia: Lippincott Williams \& Williams; 2001:329-341.

50. Jamison RN. The role of psychological testing and diagnosis in patients with pain. In: Dworkin RH, Breitbart WS, editors. Psychological Aspects of Pain: a handbook for health care providers. Progress in Pain Research and Management, Vol 27. Seattle: IASP Press; 2004:117-137.

51. McIntyre T, Johnston M, Gouveia JL, et al. Resultados psicossociais na reabilitação pós enfarte do miocárdio em mulheres portuguesase escocesas. Project POCTI/ESP/35749/1999, from the Foundation for Science and Technology (Portugal). http://alfa.fct.mctes.pt/apoios/ projectos/consulta/vglobal_projecto.phtml.en?idProjecto $=35749 \&$ sapiens=1999. Accessed June 14, 2011.

52. Diário da República article 132/2008 (Portugal). Available at: http:// www.dre.pt/. Accessed June 29, 2011.

53. Simposium Terapêutico 2008 (Portugal). Available at: http://www. simposium.pt/pagina_inicio. Accessed June 29, 2011

54. Zakrzewska JM, Lopez BC. Trigeminal and glossopharyngeal neuralgia. In: McMahon SB, Koltzenburg M, editors. Melzack's Textbook of Pain, 5th ed. London: Elsevier-Churchill Livingstone; 2006: 1001-1010.

55. Canavero S, Bonicalzi V. Drug therapy of trigeminal neuralgia. Expert Rev Neurother. 2006;6:429-440. 
56. Attal N, Cruccu G, Baron R, et al. EFNS guidelines on the pharmacological treatment of neuropathic pain: 2010 revision. Eur J Neurol. 2010;17:1113-1123.

57. Fujimaki T, Fukushima T, Miyazaki S. Percutaneous retrogasserian glycerol injection in the management of trigeminal neuralgia: long-term follow-up results. J Neurosurg. 1990;73:212-216.

58. Lee KH, Chang JW, Park YG, Chung SS. Microvascular decompression and percutaneous rhizotomy in trigeminal neuralgia. Stereotact Funct Neurosurg. 1997;68:196-199.

59. Apfelbaum RI. Neurovascular decompression: the procedure of choice? Clin Neurosurg. 2000;46:473-498.
60. Zakrzewska JM, Patsalos PN. Long-term cohort study comparing medical (oxcarbazepine) and surgical management of intractable trigeminal neuralgia. Pain. 2002;95:259-266.

61. Lefaucheur JP, Drouot X, Cunin P, et al. Motor cortex stimulation for the treatment of refractory peripheral neuropathic pain. Brain. 2009;132:1463-1471.

62. Castro AR, Siqueira SR, Perissinotti DM, Teixeira MJ, Siqueira JT. Emotional aspects of chronic orofacial pain and surgical treatment. Int J Surg. 2009;7:196-199.

\section{Publish your work in this journal}

The Journal of Pain Research is an international, peer-reviewed, open access, online journal that welcomes laboratory and clinical findings in the fields of pain research and the prevention and management of pain. Original research, reviews, symposium reports, hypothesis formation and commentaries are all considered for publication.

\section{Dovepress}

The manuscript management system is completely online and includes a very quick and fair peer-review system, which is all easy to use. Visit http://www.dovepress.com/testimonials.php to read real quotes from published authors. 